\title{
Der Palmengarten im Jahr 2018
}

Hilke Steinecke, Clemens Bayer \& Manfred Wessel

Das Jahr 2018 hat viele Veränderungen mit sich gebracht, vor allem auch im personellen Bereich. Harte Winter kommen in Frankfurt immer seltener vor. So gibt sich der Januar eher unfreundlich grau und nahezu frostfrei. Dafür illuminieren die Winterlichter wie auch in den letzten Jahren das Freiland sowie das Palmenhaus sehr geheimnisvoll. Besonders gelungen ist in diesem Jahr die Beleuchtung des kleinen Weihers. Ganz filigran leuchten die Äste der Bäume in den verschiedensten Farben. Immer wieder ein Highlight ist die Lichtwand im Oktogonbrunnen, auf der u.a. verschiedene florale Formen und ein beeindruckend dreidimensionales riesiges Herz erscheinen. Mit über 35000 Besucherinnen und Besuchern wurde der Besucherrekord des Vorjahres erneut über-

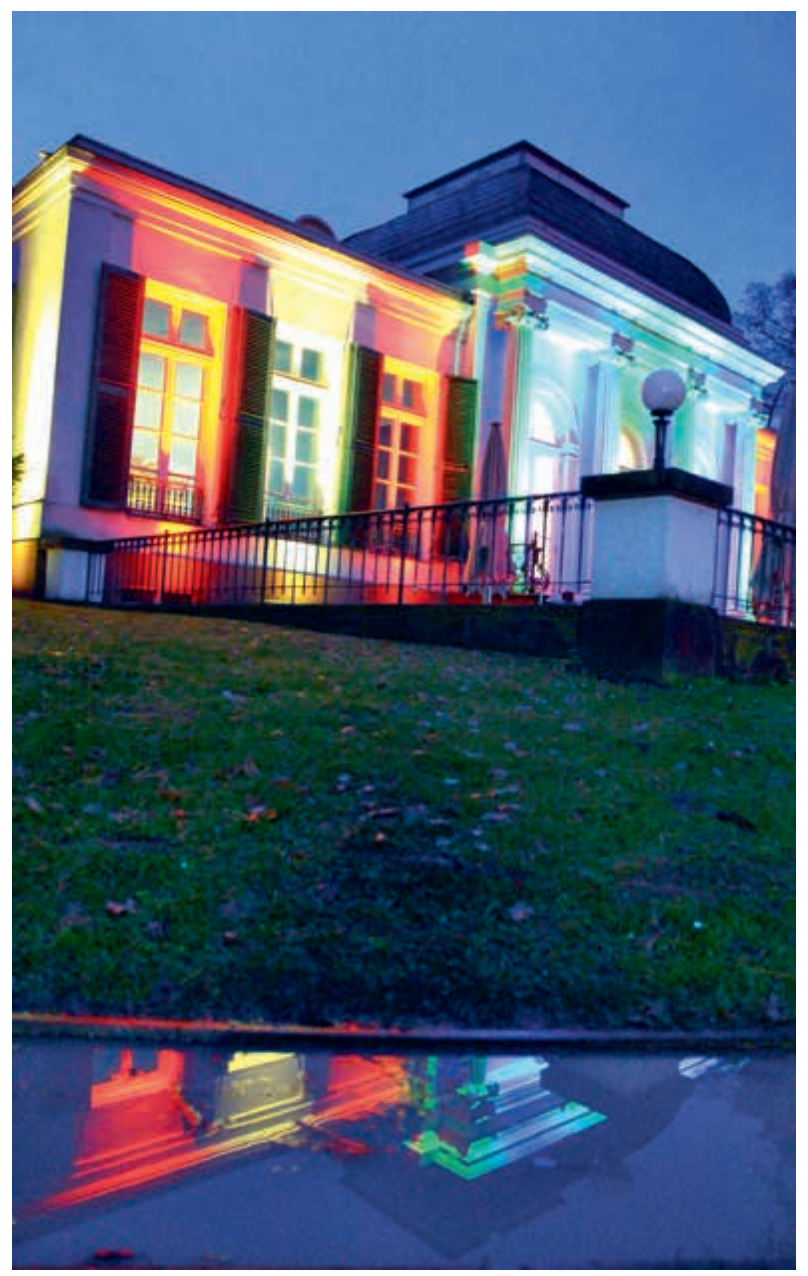

Abb 1: Auffällig bunt illuminiert ist dieses Mal die Villa Leonhardi. (Foto: H. STEINecke) schritten. Als die erste Blumenschau des Jahres zieht die Kamelienausstellung stets viele Gäste an. Die Kamelien gehören zu den ersten Sortimenten des Palmengartens, und die Präsentation dieser Pflanzensammlung in Ausstellungen hat eine lange Tradition.

Am 7. Januar kamen im Botanischen Garten 50 Interessierte zum alljährlichen Winterspaziergang zusammen, der wie üblich vom Freundeskreis des Botanischen Gartens organisiert wird. Immer wieder bewundern wir zu dieser Jahreszeit der eher kargen Vegetation die sogenannte Stinkende Nieswurz, Helleborus foetidus, deren irreführender Name nichts von der leuchtenden grünen Erscheinung verrät, die uns wie stets begeistert.

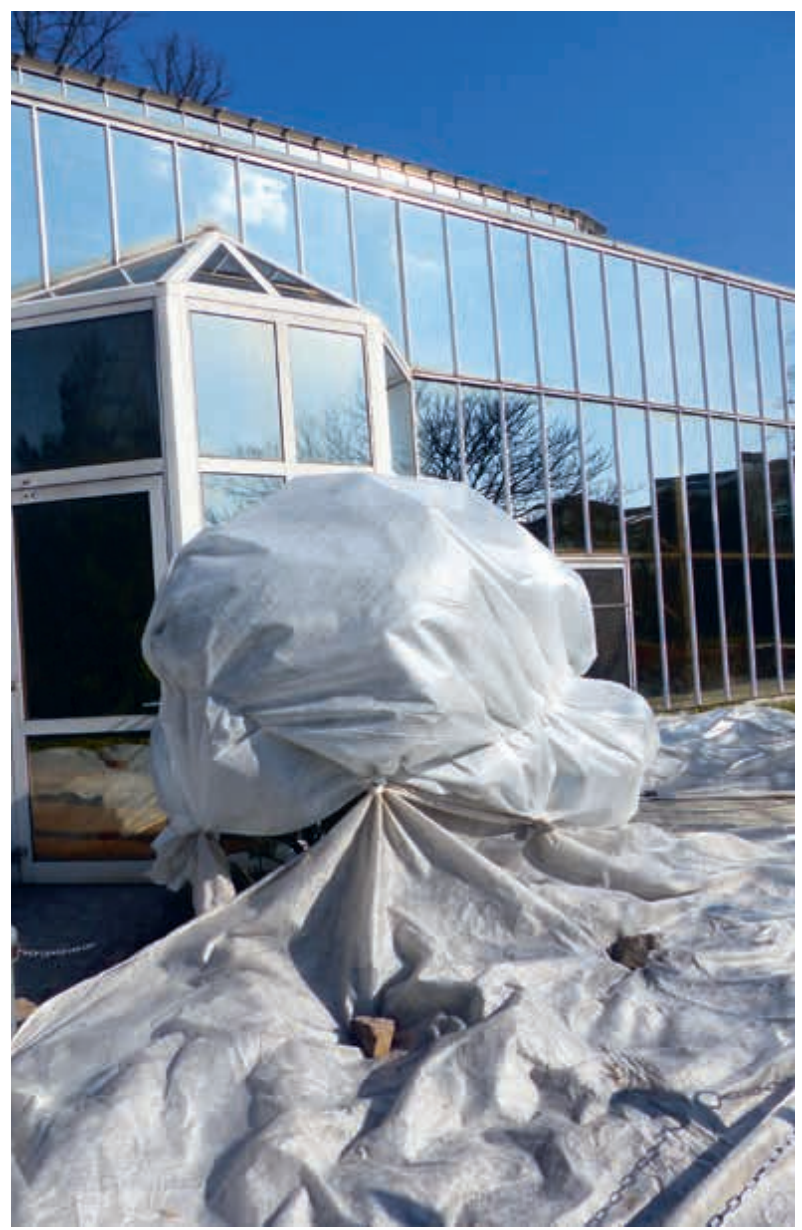

Abb. 2: Auch wenn es nur wenige Wintertage sind, setzen der Frost und die trockene Kälte den Pflanzen zu, die deshalb geschützt werden müssen. (Foto: H. STEInECKE) 


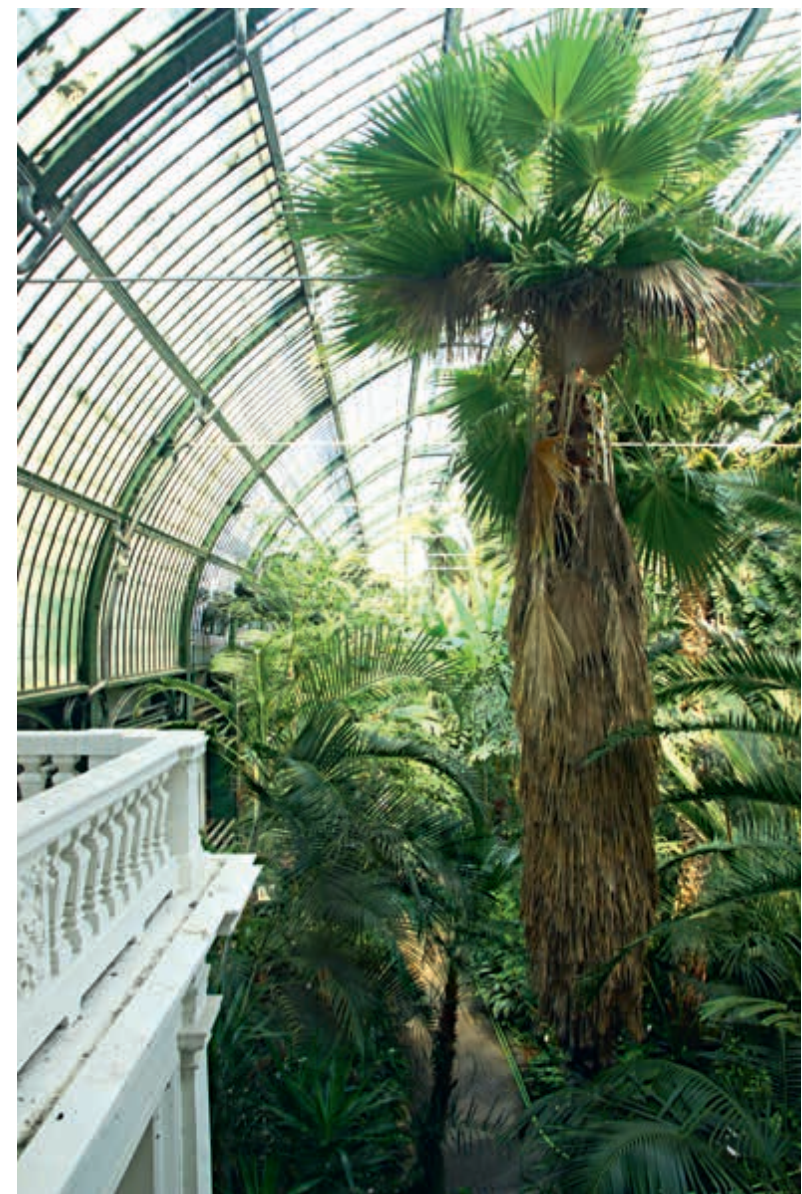

Abb. 3: Wenn es draußen ungemütlich ist, lohnt sich ein Besuch der Schauhäuser sehr, hier ein Blick vom Festsaal in das Palmenhaus. (Foto: H. STEInecke)

Eigentlich ist im Februar noch Winter, aber der Palmengarten treibt in seiner Gärtnerei Zehntausende von Zwiebelpflanzen vor, die dann in der Frühlingsblumenausstellung gezeigt werden. In dieser Saison ist dies eine besondere Herausforderung, denn ein Teil der Gewächshäuser ist abgerissen; demnächst soll der Neubau mitsamt des Blüten- und Schmetterlingshauses erfolgen. Die Ausstellung ist ein Erlebnis für Augen und Nase, denn die Frühlingsblumen erstrahlen in vielen Farben, außerdem erfüllt der süße Duft von Narzissen und Hyazinthen die Galerie. Die Eröffnung der Frühlingsblumenausstellung ist die letzte offizielle Ausstellungseröffnung unter unserem langjährigen Amtsleiter Matthias Jenny, der nun in den wohlverdienten Ruhestand geht. Am 4. Februar gibt es zu seinem Abschied einen feierlichen Festakt im Festsaal des Gesellschaftshauses. Wir wünschen ihm für seinen neuen Lebensabschnitt alles Gute. Die Frankfurter Schriftstellerin Eva

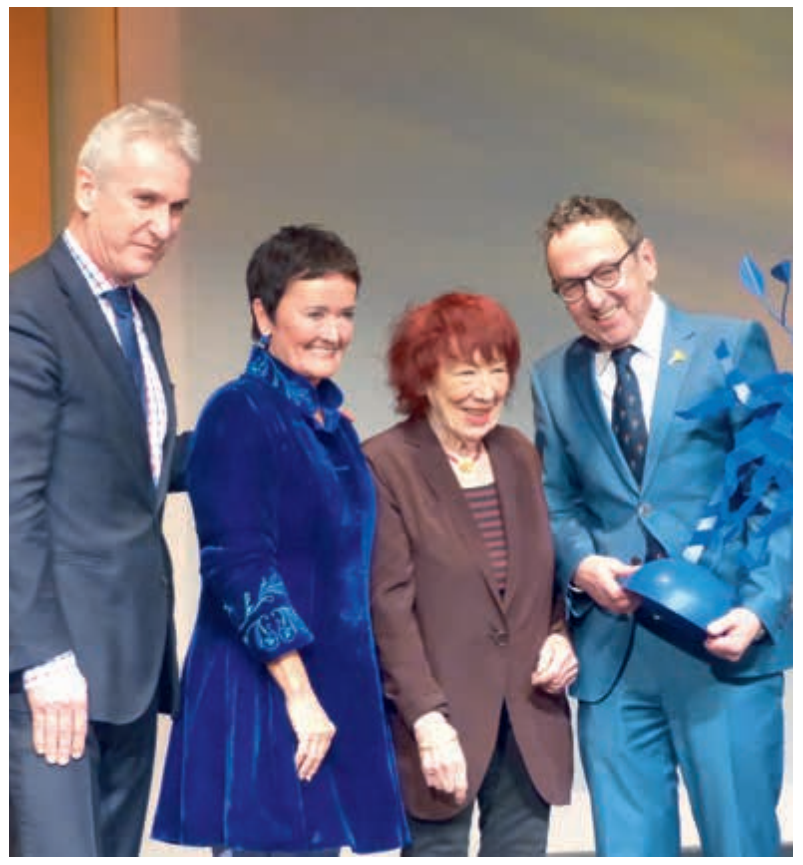

Abb. 4: Verabschiedung von Matthias Jenny in den Ruhestand. (Foto: H. Steinecke)

Deмsкi, selbst leidenschaftliche Gärtnerin, betont in ihrer literarischen Festrede, dass sich JENNY stets der Herausforderung stellen musste, dass er den apfeltragenden, kamelienblütigen Kaktus habe präsentieren müssen, obwohl der Garten ihm doch nur für eine bestimmte Zeit geliehen war und er ein „Herrscher des Gartens auf Zeit“ war. Nach den Festreden wurden „glitzernde Schmetterlinge aus Kanonen geschossen“. Der Bau eines Blütenund Schmetterlingshauses geht schließlich auf den langersehnten Wunsch von Matthias Jenny zurück und er hatte hartnäckig dafür gekämpft, dass der Bau des Hauses nun endlich umgesetzt werden kann. Mit dem Ende der Frühlingsblumenausstellung trumpft der Frühling noch einmal richtig auf, denn es wird der fünfte Frühlingsball im Festsaal, im Palmenhaus und in den Galerien gefeiert.

Am letzten Sonntag des Monats Februar öffnet der Botanische Garten zur bevorstehenden Gartensaison. An die 80 Menschen besuchen unseren Garten, der wie zu Universitätszeiten immer noch gerne als „Kleinod“ gepriesen wird, und erleben eine Führung zu den blühenden Besonderheiten. Die Gärtnerinnen und Gärtner sowie die Gartenleitung werden sich weiterhin bemühen, dem freundlichen Attribut gerecht zu werden. 


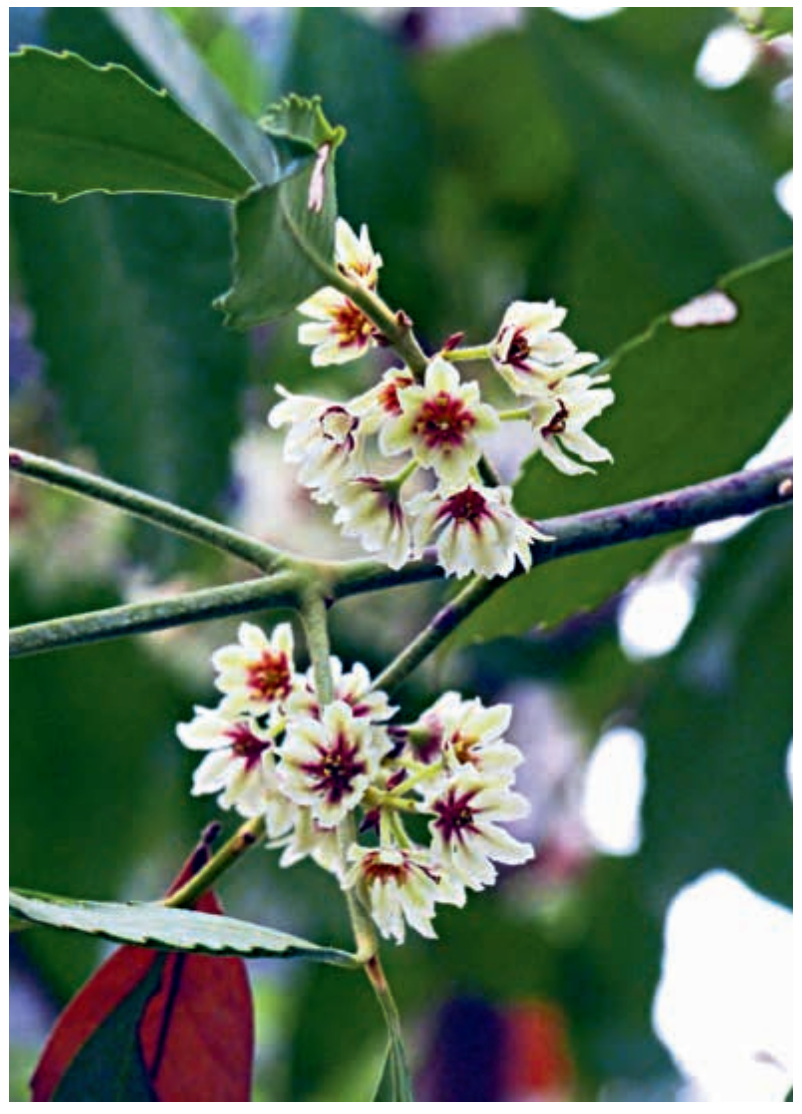

Abb. 5: Laureliopsis philippiana (Tepa) aus Chile blüht im Subantarktishaus. (Foto: H. STEINECKe)

Im März zieht die Grüne Börse viele Pflanzeninteressierte an. Es gibt viele Pflanzenraritäten zu kaufen, außerdem diverse Infos von BioFrankfurt aus dem grünen Bereich. Es wird doch noch einmal kalt, bevor der Jahrhundertsommer Frankfurt voll im Griff hat. Die Azaleenausstellung mit ihren vielen rosa Blüten macht Lust auf den Frühling. Im Foyer lockt ein großes Graffito des Künstlers Justus Becker, das eine riesige Azaleenblüte zeigt. Im Palmengarten gibt es an verschiedenen Stellen über das Jahr verteilt immer wieder Baustellen; nicht schön, aber nicht vermeidbar. Die Wasserringleitung wird in mehreren Schritten saniert, und später ist dann natürlich alles besser.

Im März widmet sich das Führungsangebot, das wie immer vom Freundeskreis des Botanischen Gartens angeboten wird, dem Frühjahrsgeophyten-Wald. Im Buchenwald gleich im Eingangsbereich konnte sich in vielen Jahrzehnten auch mit Hilfe der guten botanischen Gärtnerarbeit eine Pflanzenwelt entwickeln, die jedes Jahr aufs Neue begeistert. Busch-Windröschen, Lerchensporn,

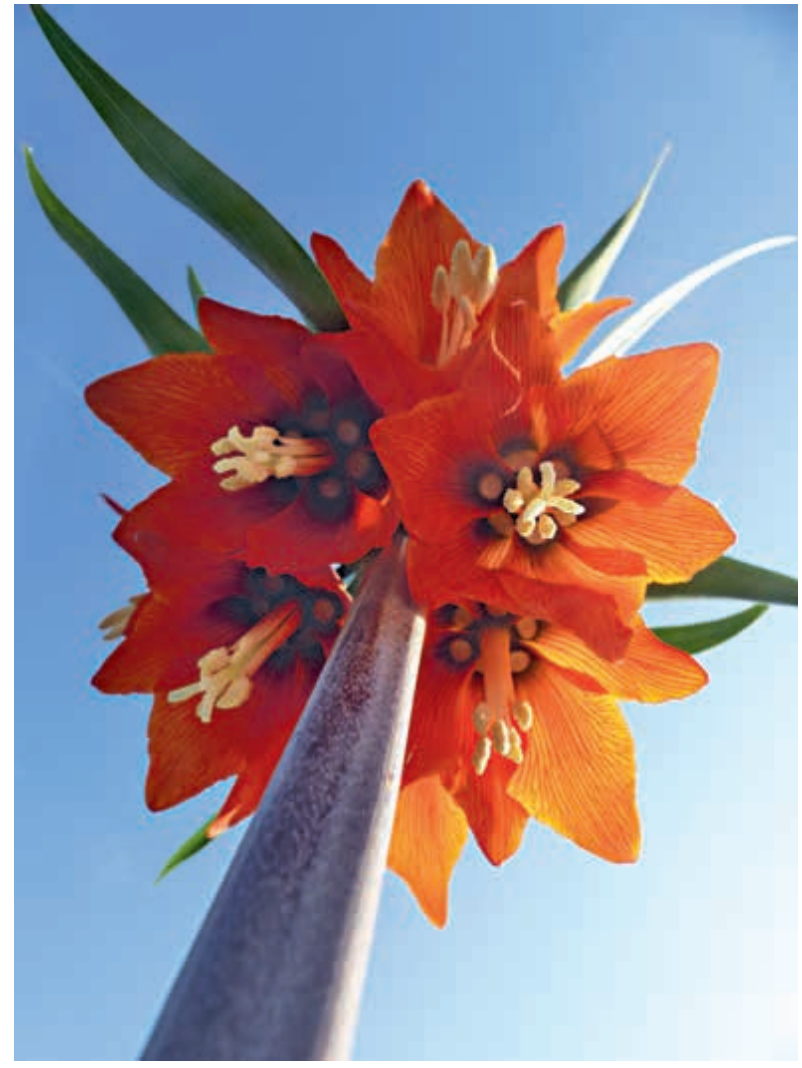

Abb. 6: Wie ein Turm wirkt diese Kaiserkrone (Fritillaria imperialis) im Frühlingsflor am Oktogonbrunnen von unten betrachtet. (Foto: H. STEInecke)

Wald-Primeln, später dann Frühjahrs-Platterbsen und viele Pflanzenarten mehr erblühen und ziehen sich dann mit Ergrünen der Waldbäume in das Erdreich zurück - ein faszinierendes Schauspiel der Natur.

Im April beginnt die große Hitze und die monatelange Trockenheit, schon in diesem Monat gibt es hochsommerliche Tage mit Temperaturen um die $30 \mathrm{Grad}$. Es ist also schon fast tropisch heiß draußen. Vielleicht ist dies ein Ausgleich dafür, dass die Feuchten Tropen des Tropicariums in diesem Jahr wegen der Sanierung geschlossen bleiben. Da es keine Temperaturrückschläge mit Spätfrösten gibt, können die Magnolien ihre Blüten in vollster Pracht entfalten. Im Laufe der letzten Jahre wurde die Magnoliengruppe auf der Wiese gegenüber der Villa Leonhardi um einzelne Exemplare erweitert. Der blühende Magnolienhain ist für etwa zwei Wochen ein Hingucker und ein viel fotografiertes Motiv. Im April tritt unser neuer Verwaltungsleiter BERnd OCHS seinen Dienst im Palmengarten an. Er ist der Nachfolger 


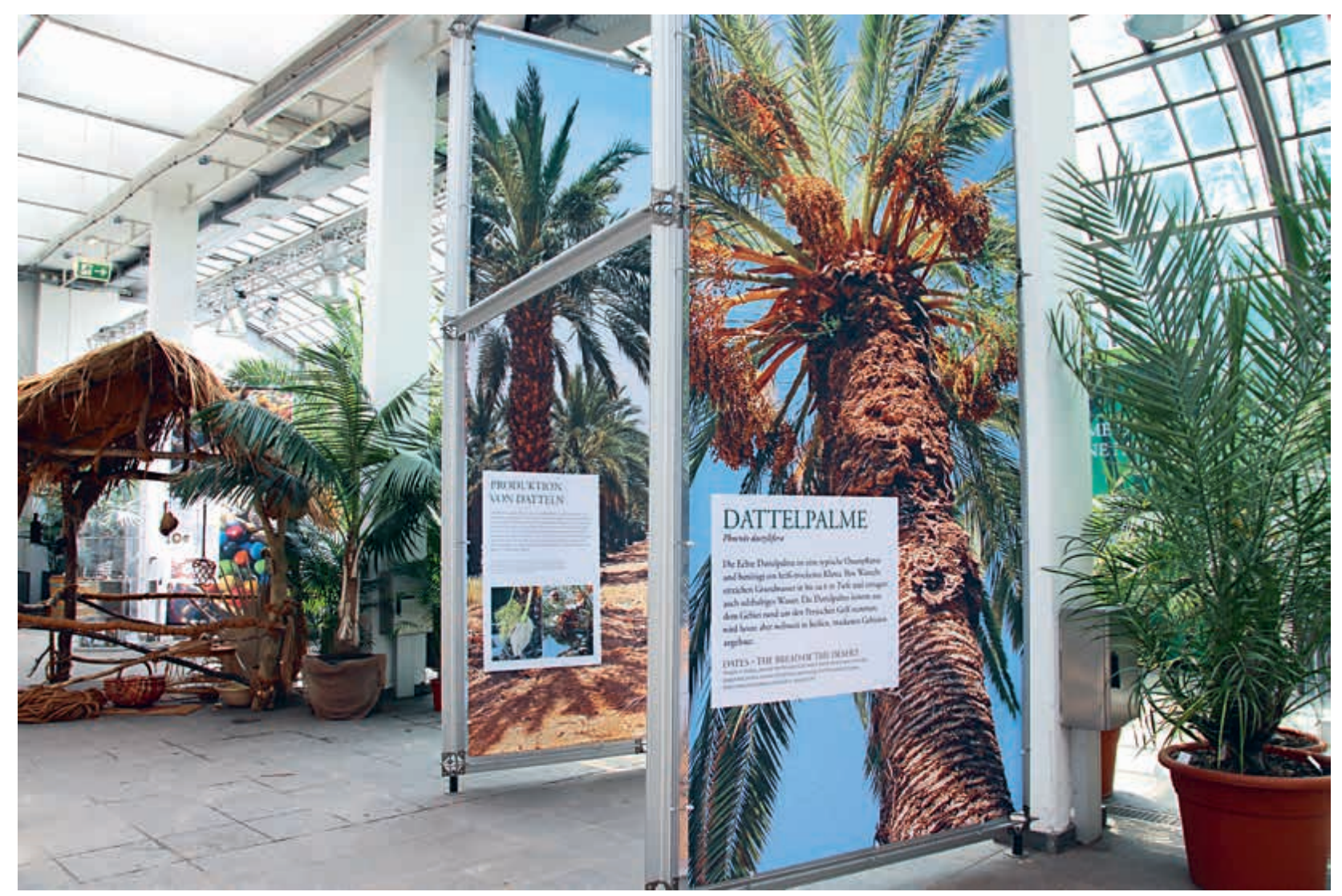

Abb. 7: Blick in die Palmenausstellung. (Foto: H. Steinecke)

von INGRID EDELMANN, die wie der Amtsleiter in den verdienten (Un)ruhestand geht. Durch eine dreimonatige Überlappungszeit ist eine sehr gute Einarbeitung in das komplexe „Gebilde Palmengarten“ möglich, das ist nicht selbstverständlich.

Der April im Botanischen Garten steht ganz im Zeichen des Projekts „Barrierefreiheit“. Dieses ist nach vier Jahren intensiver Vorarbeiten zum

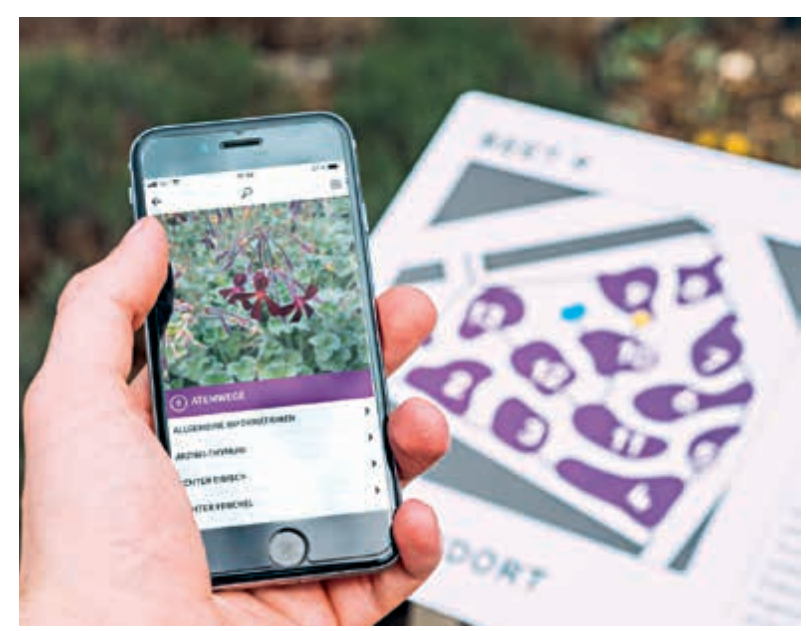

Abb. 8: Mit einer App kann nun der Senckenbergische Arzneipflanzengarten erkundet werden. (Foto: D. BRÜCHER)
Abschluss gebracht und wird in Anwesenheit der Dezernentinnen Rosemarie Heilig und Daniela Birkenfeld feierlich eröffnet. Nun stehen den Besucherinnen und Besuchern des Botanischen Gartens neue Möglichkeiten offen, den Garten und seine Pflanzen zu erleben: Bodenleitstreifen aus Basalt führen vom Eingang bis zum Senckenbergischen Arzneipflanzengarten, Informationen auf visuellen und taktilen Tafeln geben Erläuterungen und eine App mit integriertem Audioguide steht allen Smart- und I-Phone-Nutzern kostenlos zur Verfügung, um spannende und lehrreiche Geschichten zu erleben.

Ab Mai kommen die Palmen in diesem Jahr besonders groß raus. Die Sonderausstellung „Palmen" dauert bis Ende September. Wichtige Nutzpalmen wie Kokos-, Dattel- und Ölpalme werden thematisiert. Zahllose Produkte aus diversen Palmen werden vorgestellt. Es gibt viel zu entdecken, an ausgewählten Tagen begeistert ein Stand mit Produkten aus Taguanüssen, Kunsthandwerk aus Ekuador, die erstanden werden können. Ein großformatiges Foto eines tropischen Palmenstrandes 


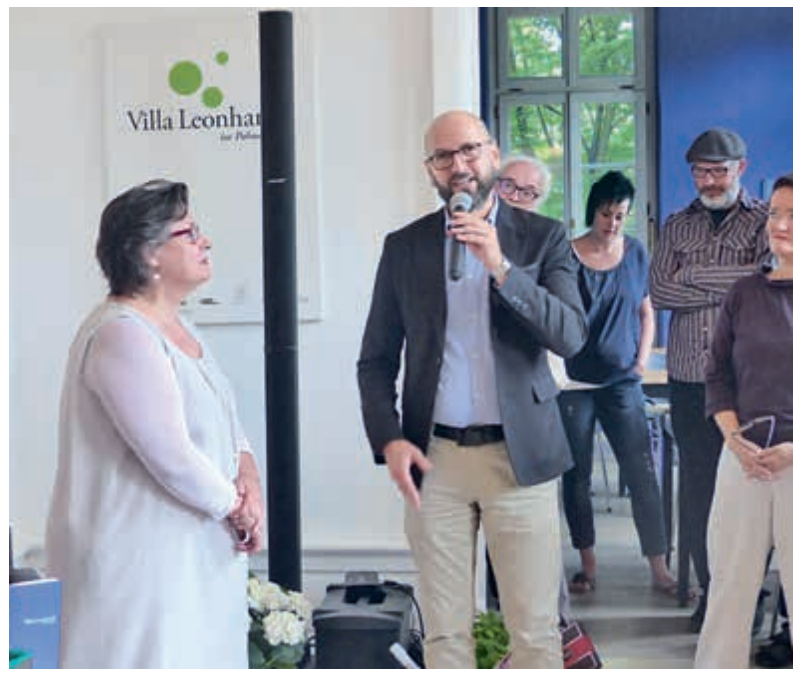

Abb. 9: Nun geht auch die Verwaltungsleiterin INGRID Edelmann in den Ruhestand. Bereits im Amt ist ihr Nachfolger Bernd Ochs, rechts im Bild. (Foto. H. Steinecke)

lädt zum Schießen von Selfies ein; man könnten meinen, gerade tatsächlich im Urlaub in der Karibik zu sein.

Die Pflanzenbörse Anfang Mai begeistert wie stets alle Pflanzeninteressierten. Zahlreiche Führungen zu den Themen „Wildkräuter, Vögel, Bienen, Stauden und Gehölze“ finden ein zahlreiches Gartenpublikum. Vor allem die „wesensgemäße Bienenhaltung", die mittels verschiedener Klotzbeuten die traditionelle Imkerei veranschaulicht, findet wieder viele interessierte Menschen, die verstanden haben, dass auch die Massentierhaltung bei den Bienen, vergleichbar der bei Schweinen, Rindern und Hühnern, nicht nur positive Aspekte hat.

Auch der Juni ist sehr heiß und trocken. Davon profitieren die vielen Sommer-Freiluft-Musikveranstaltungen, die an lauen Abenden guten Zuspruch finden. Der Bau des Blüten- und Schmetterlingshauses verzögert sich weiter, es steht nun fest, dass es mit den Bauarbeiten erst im kommenden Jahr wieder richtig weitergehen kann. Zum Jubiläumsjahr 2021 sollen aber tropische Schmetterlinge fliegen. Anfang Juni, kurz vor dem Rosen- und Lichterfest, tobt ein Unwetter über Frankfurt und dem Palmengarten, ein Blitz schlägt ins Palmenhaus ein und viele Bereiche sind landunter. Die Kanalisation ist völlig überlastet, in der Palmenausstellung steht das Wasser knöchel-

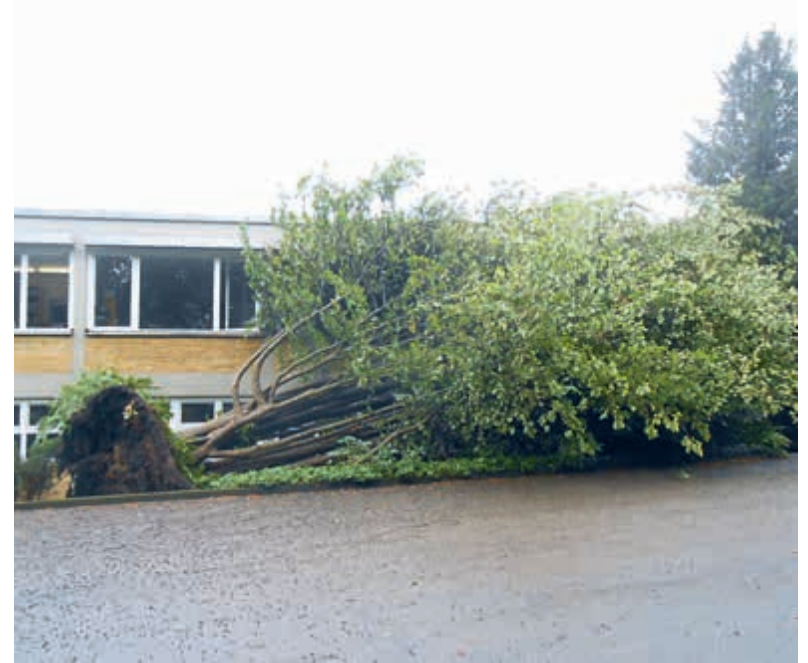

Abb. 10: Der schöne Eisenholzbaum (Parrotia persica) im Botanischen Garten ist ein Opfer des Sommer-Unwetters. (Foto: M. Wessel)

hoch. Auch während des Rosen- und Lichterfestes ist das Wetter unsicher, so dass diesmal weniger Besucherinnen und Besucher als sonst bis zum Feuerwerk bleiben und die Veranstaltung um ein Haar wegen eines herannahenden Unwetters beendet werden musste. In der Rosenausstellung ist es so heiß, dass Eisblöcke kühlen sollen und vermeiden sollen, dass die Rosen zu schnell welken.

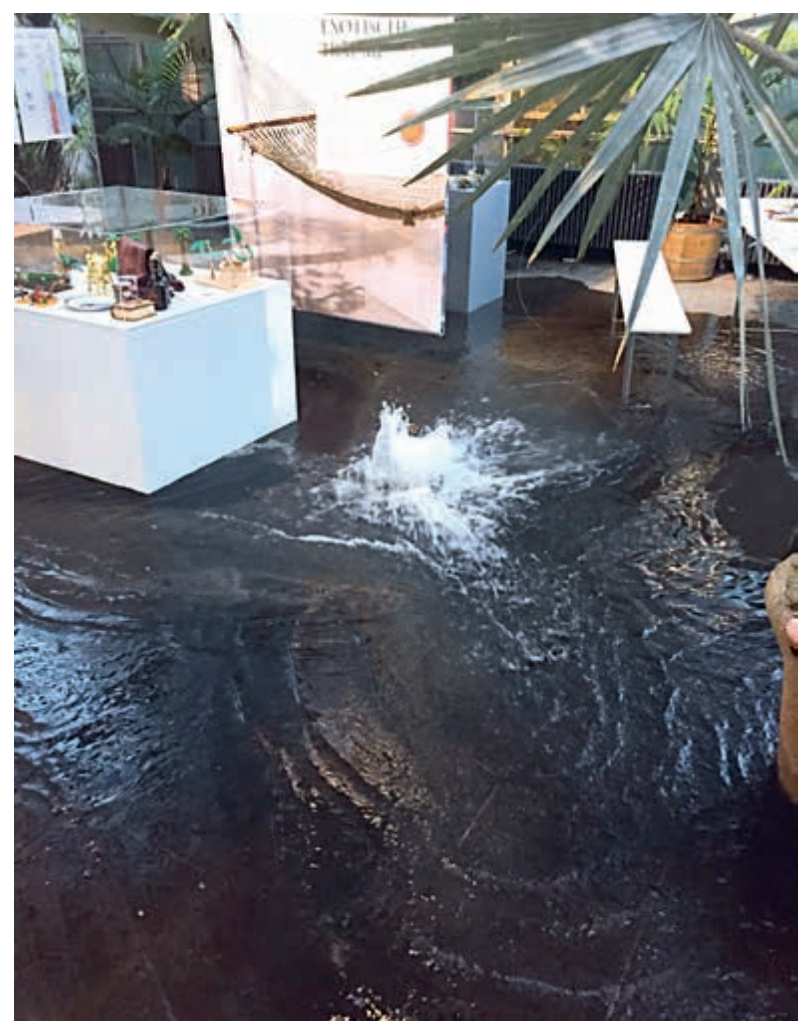

Abb. 11: Das Unwetter sorgt im Palmengarten für Landunter in der Palmenausstellung. (Foto: J. GLaser) 


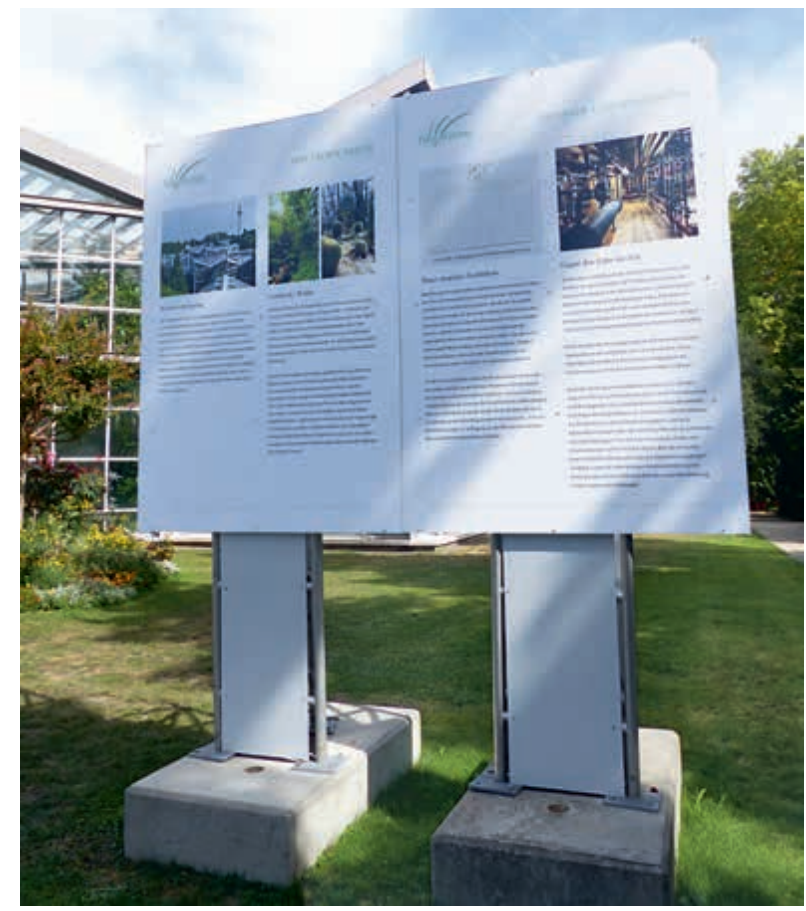

Abb. 12: Hinweisschild auf die Sanierung und Teilsperrung des Tropicariums. (Foto: H. Steinecke)

INGRID EDELMANN verabschiedet sich aus ihrer aktiven Arbeitsphase im Palmengarten.

A Midsummer Night's Dream im Botanischen Garten - den ganzen Juni über finden Freilufttheater-Aufführungen des Shakespeare-Ensembles von "The Loft Frankfurt" statt. Alle sind in Bewegung, die Schauspielerinnen und Schauspieler wie auch das Publikum wandern während der Vorstellung zu verschiedenen Standorten im Botanischen Garten und lauschen den in Englisch vorgetragenen Texten. Es ist ein großer Spaß und

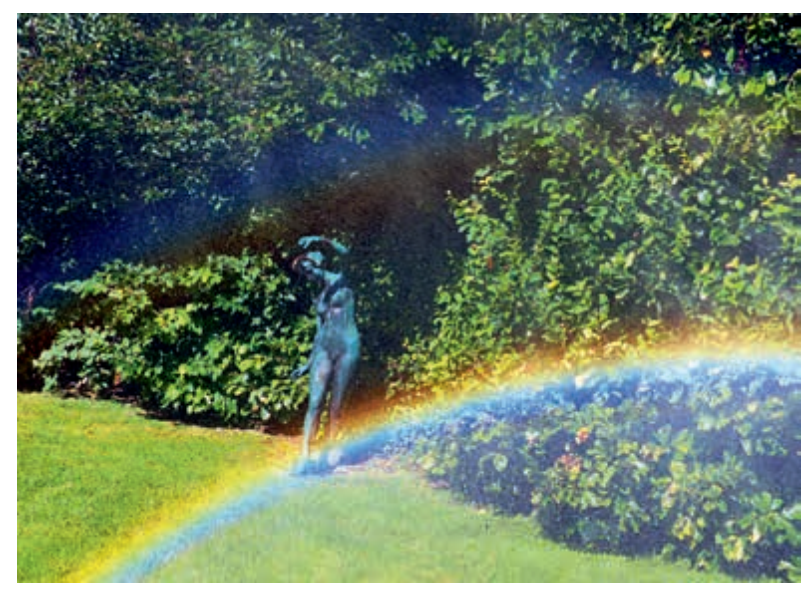

Abb. 13: Im heißen Sommer ist das Wässern der Pflanzen die wichtigste Aufgabe. Im Wasserstrahl ergeben sich manchmal schöne Regenbögen. (Foto: H. STEINeCKe) auch das Wetter spielt sehr gut mit, was natürlich besonders positiv ist, wenn man kein Dach über dem Kopf hat. Allerdings: der $90 \mathrm{~mm}$-Starkregen, der Anfang des Monats innerhalb von 35 Minuten vom Himmel fiel, hat gravierende Folgen im Garten: Wegeausspülungen massivster Art und Baumschäden bis hin zum Totalverlust des großen alten Eisenholzes vor dem Wirtschaftsgebäude lösen Trauer aus.

Im Juli ist Hochsaison für die Steppenpflanzung. Die naturnah gestalteten Bereiche vom Mittelmeer bis zur amerikanischen Prärie sind Hitze und Trockenheit gewappnet und sehen auch dann noch ohne übermäßige Wasserzufuhr recht frisch aus, während im Frankfurter Stadtgebiet viele Rasenflächen verdorrt sind. Aufgrund des Blütenreichtums ist die Palmengarten-Steppe Lebensraum für zahlreiche Insekten. Schöne Farbkontraste liefern im Sommer die Gelbe Schafsgarbe und die Blauraute. Auch die Pelargonienpflanzung am Haus Leonhardsbrunn ist sehr beliebt. Besonders bei Hitze entströmt den Blättern diverser Sorten ein Duft nach Zitrus, Minze oder Schokolade.

Die extreme Trockenheit und Hitze bedingen volle Konzentration in der täglichen gärtnerischen Arbeit auf die Lebenserhaltung der uns anvertrauten Gewächse. Nur mit großem Aufwand sind Trockenschäden zu vermeiden, wenn auch die Trockenstandorte mit angepassten Pflanzengemeinschaften, die im Botanischen Garten mehrfach zu finden sind, noch am besten mit den Bedingungen fertig werden und keine Bewässerung nötig haben. Viele Pflanzenarten schließen ihren Jahreszyklus aber schneller ab als gewohnt und führen dadurch zu teils unerwarteten Vegetationsbildern, an die sich die Besucherinnen und Besucher erst gewöhnen müssen.

Manche Pflanzen profitieren von dem Extremsommer und blühen besonders reichlich wie diverse Kakteen. Auch der Riesen-Hibiskus, der es zwar feucht mag, aber auch sehr warm, zeigt im August eine besonders reichliche Blütenpracht. Die Pflanzen werden natürlich regelmäßig gegossen. Der Wasserverbrauch im Palmengarten lag in 2017 


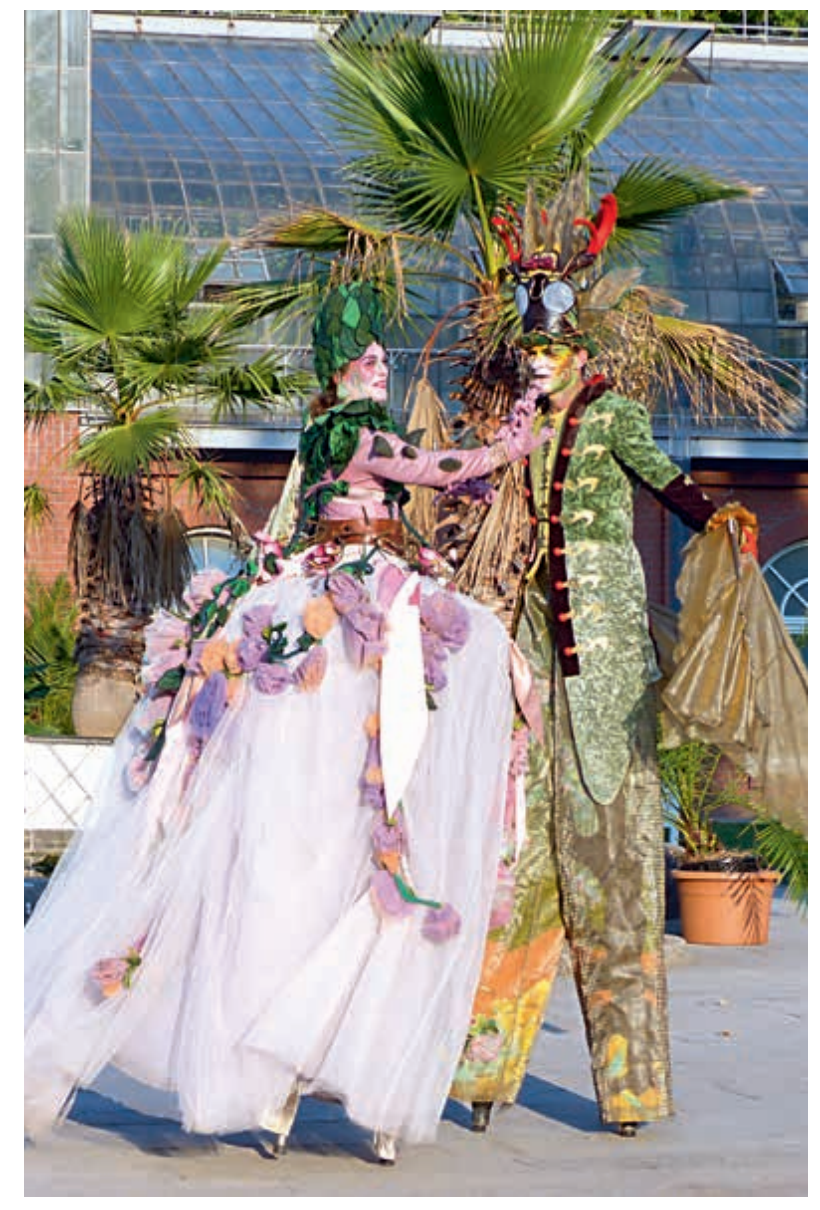

Abb. 14: Traditionell begrüßen zwei Stelzenläufer die Gäste des Jahresempfangs. (Foto: H. STEIneCKe)

bei ca. $98000 \mathrm{~m}^{3}$, im Botanischen Garten bei ca. $28000 \mathrm{~m}^{3}$, in 2018 sind es ca. $124000 \mathrm{~m}^{3}$, im Botanischen Garten etwa $35000 \mathrm{~m}^{3}$. Im heißen Sommer 2018 wird eine Ablesung unseres Hauptwasserzählers in der Siesmayerstraße vorgenommen, zu einem Zeitpunkt, zu dem fast alle Regner im Garten laufen. In dem Moment ist ein Verbrauch von ca. $130 \mathrm{~m}^{3}$ pro Stunde gemessen. Wenn man davon ausgeht, dass die Gärtnerinnen und Gärtner sieben Stunden pro Tag wässern, dann kann der Tagesverbrauch durchaus bei ca. $1000 \mathrm{~m}^{3}$ liegen.

Auch im August locken Führungen zu kulinarischen Themen, wie Brombeeren und eßbare Blüten. Das Schöne daran ist, dass z. B. Brombeeren im Botanischen Garten als ,ein Spiegelbild der Biodiversität" vorgestellt werden und damit über die Kulinarik lehrreiche Informationen an die Frau und den Mann liefern. Wie heißt es so schön: „Liebe geht durch den Magen.“- und bei uns eben auch die Wissensvermittlung.

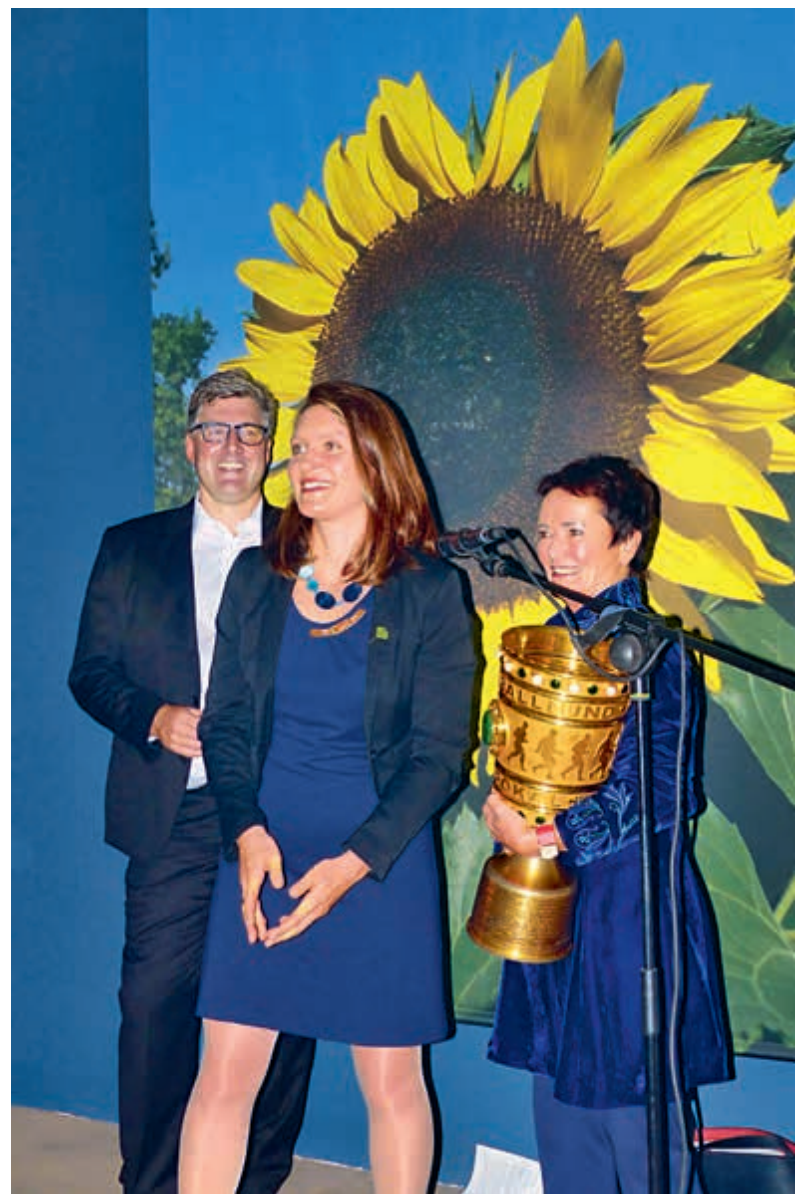

Abb. 15: Die neue Direktorin Katja Нeubach stellt sich während des Jahresempfangs vor. (Foto: H. STEIneCKe)

Zum 1. September beginnt unsere neue Leiterin, Katja Heubach, ihren Dienst als Palmengarten-Direktorin. Viele Aufgaben und Herausforderungen warten auf sie. Wir heißen sie herzlich willkommen. Ihre erste öffentliche Rede im Palmengarten hält sie auf dem Jahresempfang in der Galerie. Als Ehrengast dabei ist auch Axel Hellmann, Vorstandsmitglied von Eintracht Frankfurt. Er hat den DFB-Pokal, der ein ganzes Jahr beim besten deutschen Fußballverein in der Vitrine stand, mitgebracht. Gleichzeitig mit der Direktorin beginnt nun auch Patricia Germandi im Palmengarten. Sie besetzt nun die neu geschaffene Stelle der Leitung der Abteilung Kommunikation und Veranstaltungen. Die neue Abteilung ist noch im Aufbau, so dass der Palmengarten in Zukunft mehr Kapazitäten, Chancen und Möglichkeiten haben wird, z. B. Veranstaltungen, Medienpräsenz und öffentlichkeitswirksame Aktionen zu realisieren. Bunt geht es stets beim Herbstfest, einem beliebten Fest für 


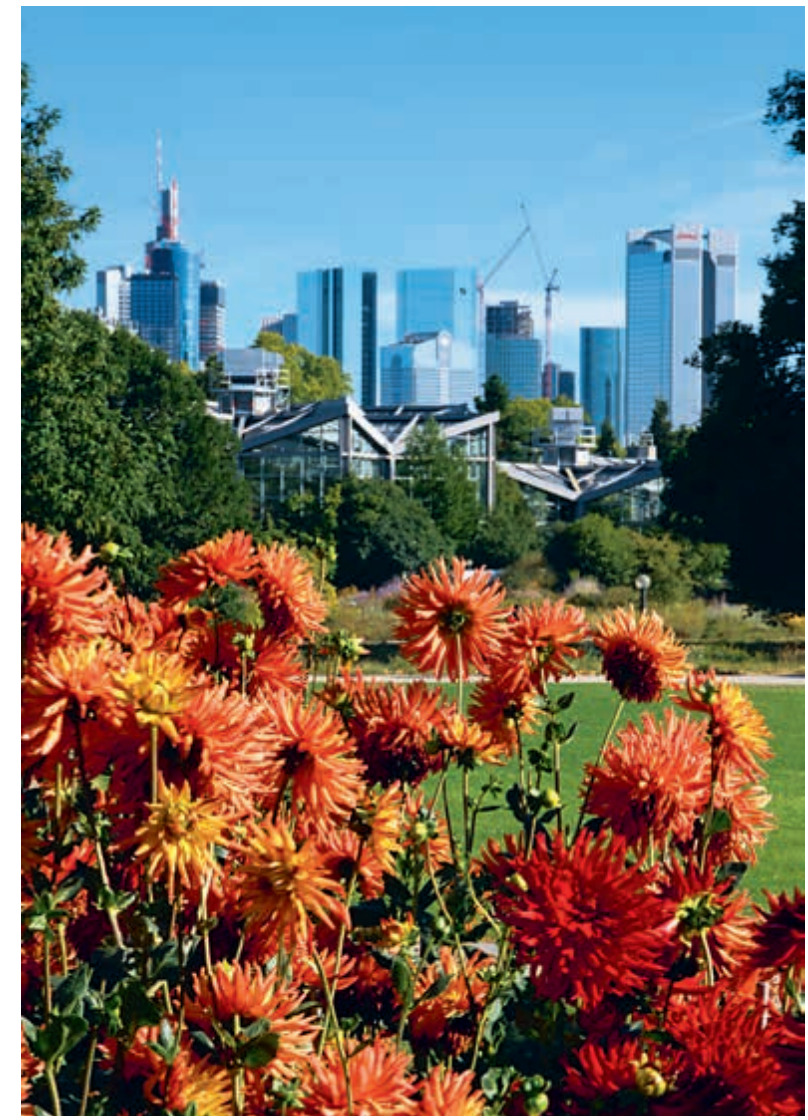

Abb. 16: In jedem Herbst ein wunderbarer Kontrast: Dahlienrondell, Tropicarium und Frankfurter Skyline. (Foto: H. STeinecke) die ganze Familie, zu. Wie in jedem Jahr präsentiert sich der Palmengarten im Herbst auf dem Fürstlichen Gartenfest in Langen. Das Motto des diesjährigen Festes ist Italien. Wir haben einen Marktstand mit verschiedenen Früchten aus Italien aufgebaut. Aber auch diverse Citrus-Pflanzen lassen grüßen in Anlehnung an Goethe, dass Italien das Land ist, in dem die Zitronen blühen. Gleichzeitig ist dies eine schöne Vorankündigung der großen Citrus-Ausstellung 2019, an der wir intensiv arbeiten.

Der nunmehr bereits 22. Tag der offenen Tür im Botanischen Garten findet wieder ein dankbares Publikum. Langjährige, externe Freunde und Begleiter des Botanischen Gartens bereichern wie stets das Angebot: der NABU-Ortsverein Frankfurt am Main, der BUND, der Holzbildhauer EKKahard Bouchon, der Nizza-Gärtner Rainer Gesell, die Drechsler Klaus-Dieter Hedrich und Stephan Richter, sie alle füllen den Tag zusammen mit den vielen Aktiven des Freundeskreises mit Leben. Das Bienenfestival am Monatsende bildet noch einmal einen Saisonhöhepunkt und zahlreiche Menschen bevölkern den Botani-

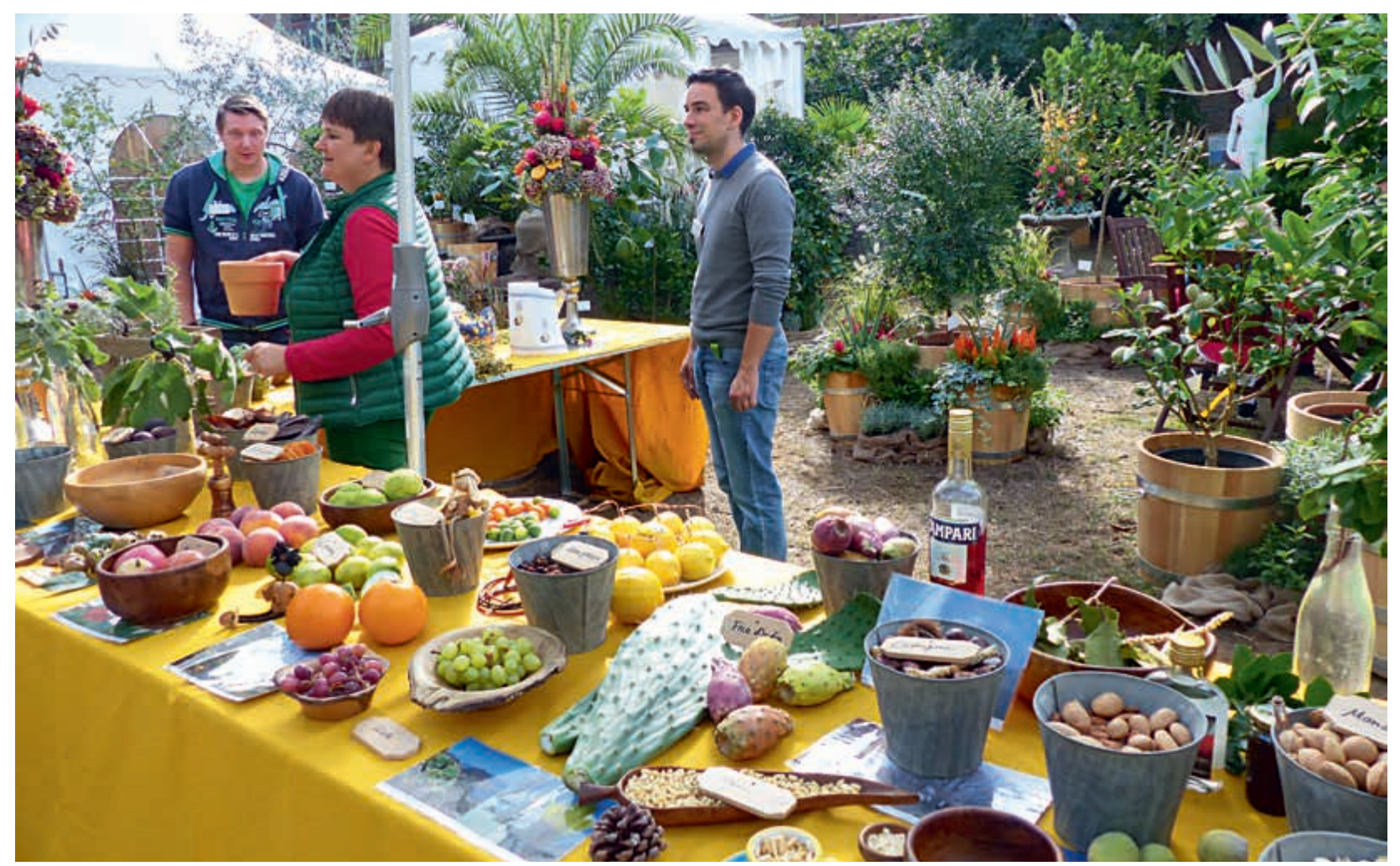

Abb. 17: Der Palmengarten mit seinem Informationsstand auf dem Fürstlichen Gartenfest auf Schloss Wolfsgarten. (Foto: H. STeinecke) 
schen Garten - neben den Bienen, die den ganzen Sommer schon ein recht sorgenfreies Leben bei uns führen konnten.

Die vielen Dahlien vor dem Haus Leonhardsbrunn sowie die Ausstellung „Blumen des Herbstes" bringen im Oktober reichlich Farbe in den Herbst. Viele Bäume haben dagegen schon früh vertrocknetes Laub abgeworfen, ohne dass sie richtig bunt werden.

Der Oktober beschließt ein ereignisreiches Gartenjahr im Botanischen Garten. Die Vielfalt der Pilze und der Reichtum der Apfelsorten erstaunt die Teilnehmerinnen und Teilnehmer der letzten Führungen des Freundeskreises. Am 1. November kehrt, zumindest was die Anzahl der Köpfe im Garten betrifft, relative Ruhe ein. Die Winterbaustellen werden in Angriff genommen, die erste große Aufgabe der beginnenden sogenannten „kalten Jahreszeit" ist die notwendige Entschlammung des Teiches und die Reduzierung des überhand genommenen Pflanzenbewuchses in demselben. Auch die Belegschaft des Botanischen Gartens freut sich auf das bevorstehende Gartenjahr 2019.

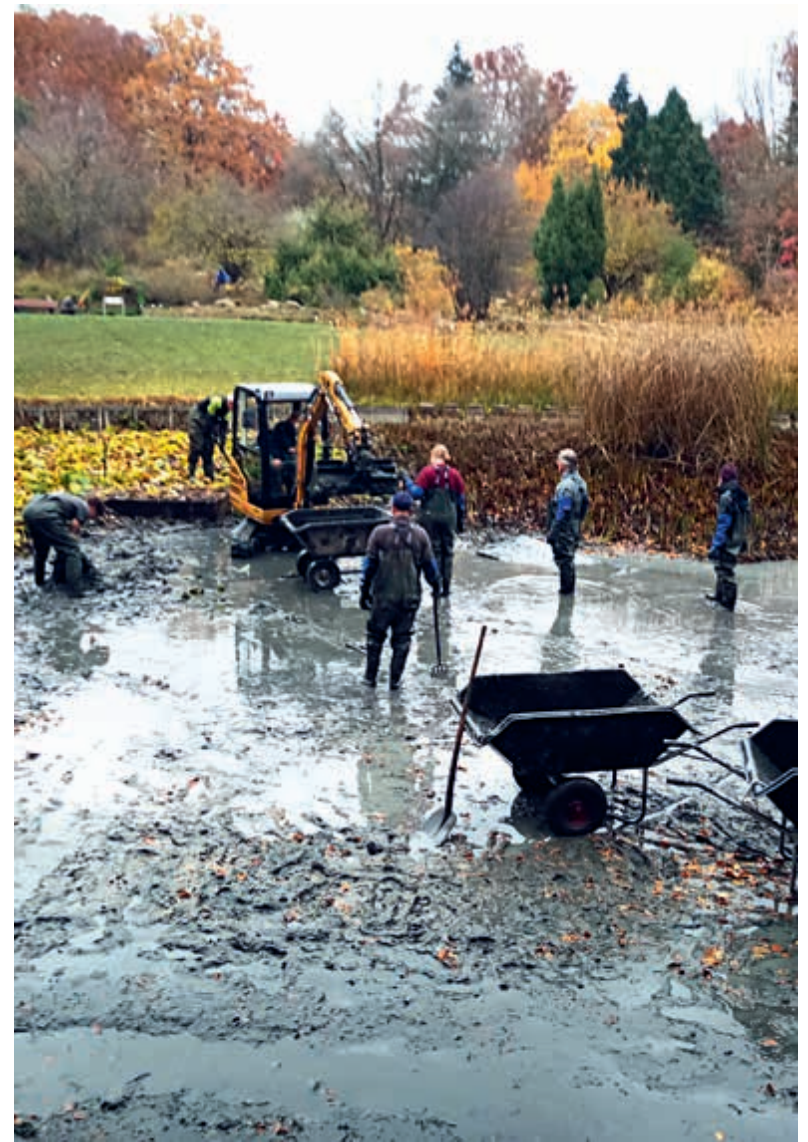

Abb. 18: Entschlammung des Teiches im Botanischen Garten. (Foto: E. BRUde)

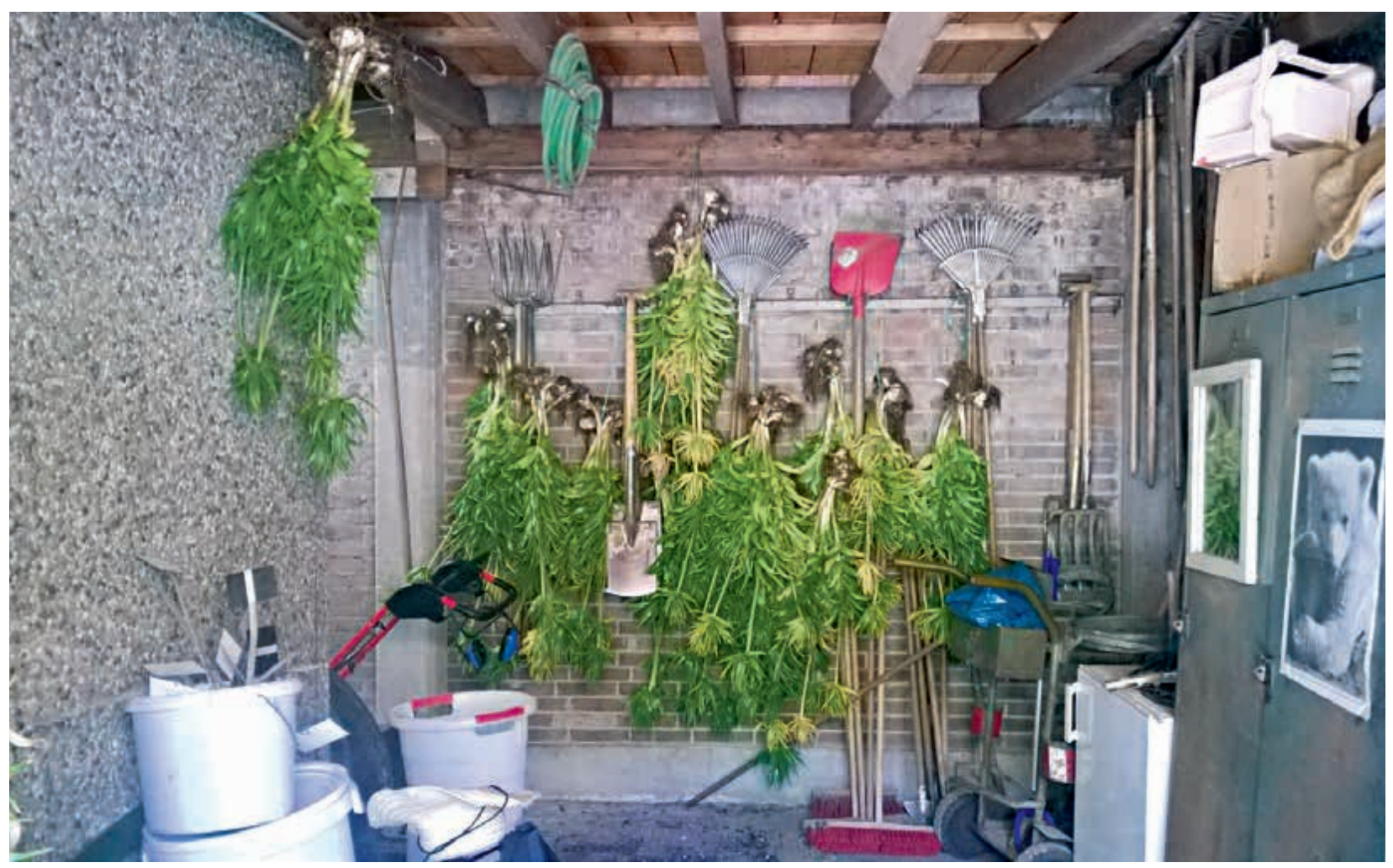

Abb. 19: „Palmengarten-Idylle“. Nicht winterharte Zwiebeln, Knollen und Rhizome müssen ins Überwinterungsquartier. (Foto: S. SEITZ) 


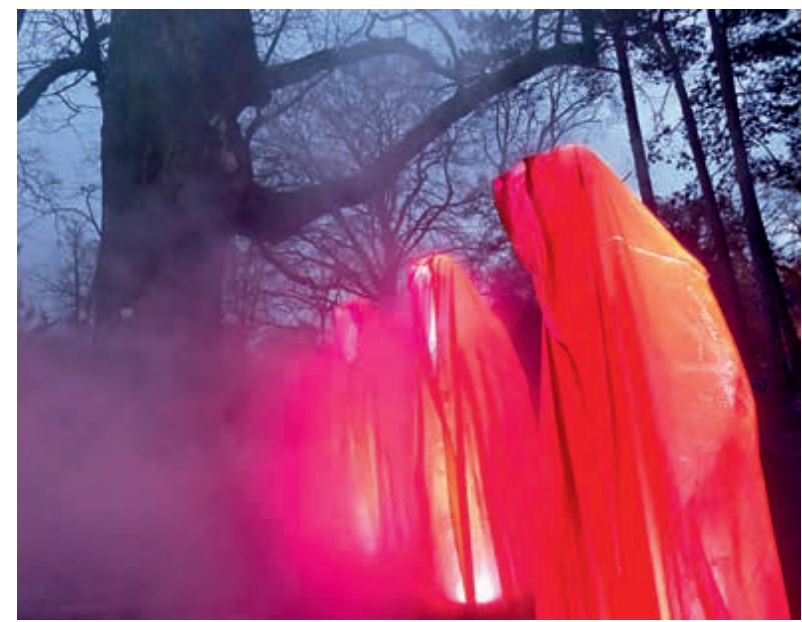

Abb. 20: Die magisch leuchtenden „Wächter der Zeit“ im Dezember während der Winterlichter. (Foto. H. STEInecke)

Sehr beliebt sind auch die botanischen Zeichnungen der Society of Botanical Artists. Das Motto lautet „The seasonal garden“. Die Ausstellung wird bis in den November in der Galerie Ost gezeigt. Selbst in dem üblicherweise nasskalten Novembermonat ist es draußen noch so schön, dass sich Besucherinnen und Besucher auf den Liegen auf der Liegewiese sonnen.

Der Dezember steht im Zeichen der Weihnachtsausstellung. Es ist vorerst die letzte Weihnachtsausstellung dieser Art im Palmengarten, es gibt aber bereits Ideen für andere Veranstaltungs-

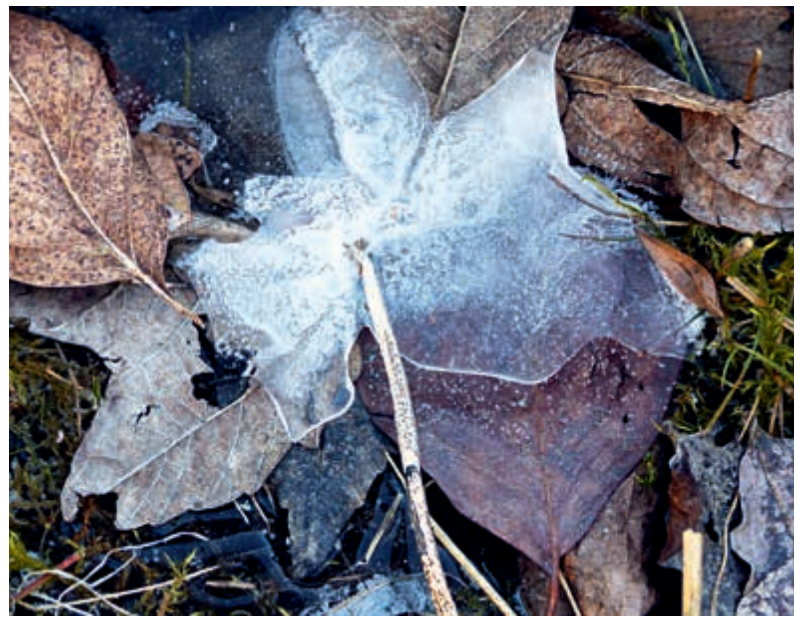

Abb. 21: Auch der Winter hat im Garten seine schönen Seiten. „Doppelblatt“ mit Eiskappe. (Foto: H. STEInecke)

formate im Winter. Und natürlich strahlen wieder die Winterlichter. Besonders beliebt sind in dieser Saison die großen leuchtenden Pusteblumen vor dem Direktionsgebäude, die am ersten Wochenende sogar im Schnee stehen. Magisch wirken die rot leuchtenden, von Nebel umwaberten roten „Wächter der Zeit" sowie die 36 Würfel, die im Takt zu Tschaikowskys Dornröschenwalzer blinken.

Nun schauen wir einem spannenden Gartenjahr 2019 entgegen.

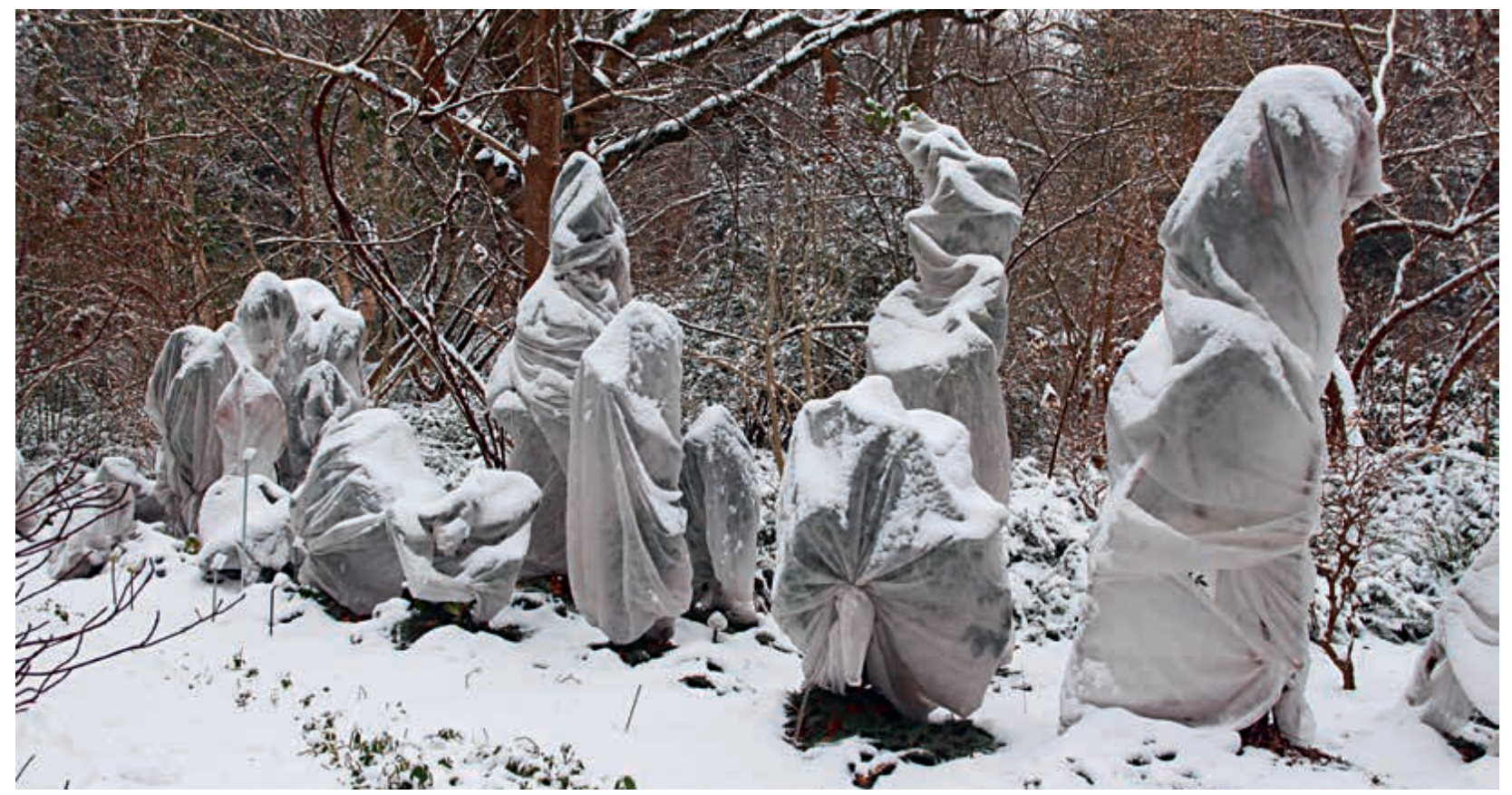

Abb. 22: Wie die sieben Zwerge aus dem Märchen wirken die vor Frost geschützten und mit Vlies verpackten Pflanzen im Botanischen Garten. (Foto: H. STEInecke) 